\title{
Prime Harmonious Labeling of Some New Graphs
}

\author{
P.Deepa ${ }^{1}$, S. Uma Maheswari ${ }^{2}$, K. Indirani ${ }^{3}$ \\ ${ }^{I}$ Department of Mathematics, CMS College of Science And Commerce, Coimbatore, India \\ ${ }^{2}$ Asst.professor, Department of Mathematics, CMS College of Science And Commerce, Coimbatore, India \\ ${ }^{3}$ Head and Asso. Professor, Department of Mathematics, Nirmala College For Women, Coimbatore, India
}

Abstract: In this paper we have introduced prime harmonious labeling of some new graphs. We prove that the graphs Fan $f_{n}$, Star $S_{n}$, Comb graph $P_{n} . K_{n}$, Crown graph $C_{n} . K_{l, n}$, Bistar $B_{n, n}$, Middle graph $M\left(P_{n}\right)$ and paths are prime harmonious labeling.

Keywords: Prime labeling, Harmonious labeling, Prime harmonious labeling, Bistar $B_{n, n}$, Middle graph $M\left(P_{n}\right)$.

\section{Introduction}

All graphs in this paper are finite, simple and undirected. The symbolsV(G) and $\mathrm{E}(\mathrm{G})$ will denote the vertex and edge set of the graph G. For standard terminology and notations we follow Gross and Yellon [5]. We will provide brief summary of definitions and other information which are necessary for the present investigations.

Definition 1.1: Let $G=G(V, E)$ be a graph. A bijection $f: V \rightarrow\{1,2,3 \ldots \ldots .,|v|\}$ is called prime labeling if for each edge $\mathrm{e}=\{\mathrm{u}, \mathrm{v}\}$ belong to $\mathrm{E}$, we have $\operatorname{GCD}(\mathrm{f}(\mathrm{u}), \mathrm{f}(\mathrm{v}))=1$. A graph which admits a prime labeling is called a prime graph.

Definition 1.2: Let $G$ be a graph with $q$ edges. A function $f$ is called harmonious labeling of graph $G$ if $f: V \rightarrow$ $\{0,1,2,3 \ldots \ldots, \mathrm{q}-1\}$ is injective and the induced functionf ${ }^{*}: \mathrm{E}(\mathrm{G}) \rightarrow\{0,1,2, \ldots \mathrm{q}\}$ defined as $\mathrm{f}^{*}(\mathrm{e}=\mathrm{uv})=(\mathrm{f}(\mathrm{u})+$ $\mathrm{f}(\mathrm{v}))(\bmod \mathrm{q})$ is bijective. A graph which admits a harmonious labeling is called a harmonious graph.

Definition 1.3: Let $G$ be a graph with $q$ edges. A function $f$ is called prime harmonious labeling of graph $G$ if $f$ $: \mathrm{V} \rightarrow\{0,1,2,3 \ldots \ldots, 2 \mathrm{q}-1\}$ is injective and the induced function $\mathrm{f}^{*}: \mathrm{E}(\mathrm{G}) \rightarrow\{0,1,2, \ldots .2 \mathrm{q}\}$ is defined by

$f^{*}(e=u v)=\left\{\begin{array}{c}G C D(f(u), f(v))=1 \quad \text { and } \\ f(e=u v)=(f(u)+f(v))(\bmod q)\end{array}\right.$

A graph which satisfies the conditions of prime labeling and harmonious labeling is called a prime harmonious labeling. A graph which admits a prime harmonious labeling is called a prime harmonious graph and it is denoted by $\mathrm{P}_{\mathrm{H}}$.

Definition 1.4: The fan $f_{n}(n \geq 2)$ is obtained by joining all vertices of $P_{n}$ (Path of $n$ vertices)to a further vertex called the center and contains $n+1$ vertex and $2 n-1$ edges (i.e) $f_{n}=P_{n}+K_{1}$.

Definition 1.5: A star $S_{n}$ is the complete bipartite graph $K_{1, n}$ is a tree with one internal node and $n$ leaves.

Definition 1.6: The graph obtained by joining a pendent edge at each vertex of a path $P_{n}$ is called a comb and is denoted by $\mathrm{P}_{\mathrm{n}}$. $\mathrm{K}_{\mathrm{n}}$ or $\mathrm{P}_{\mathrm{n}}^{+}$.

Definition 1.7: A cycle $C_{n}$ is a simple graph in which the start and end vertices are same.

Definition 1.8: A crown graph is obtained by joining $K_{1, n}$ vertices at each vertex of the cycle $C_{n}$ and it is denoted by

$\mathrm{C}_{\mathrm{n}} \cdot \mathrm{K}_{1, \mathrm{n}}$.

Definition 1.9:The middle graph $M(G)$ of a graph $G$ is the graph whose vertex set is $V(G) \cup E(G)$ and in which two vertices are adjacent if and only if either they are adjacent edges of $G$ or one is a vertex of $G$ and the other is an edge incident with it.

Definition 1.10: Bistar is the graph obtained by joining the apex vertices of two copies of star $\mathrm{K}_{1, \mathrm{n}}$.

Definition 1.11: By a graph $\mathrm{P}_{\mathrm{n}}{ }^{2}$, we mean the graph obtained from $\mathrm{P}_{\mathrm{n}}$ joining each pair of vertices at distance 2 in $P_{n}$.

\section{Main Result}

In this paper we prove that the Path $P_{n}, K_{1, n}$, Cycle ,Comb, Crown $C_{n}$. $K_{1, n}$ and the Fan $f_{n}$, Bistar $B_{n, n}$, Middle graph $\mathrm{M}\left(\mathrm{P}_{\mathrm{n}}\right)$ are prime harmoniouslabeling.

Theorem 2.1: The Path $P_{n}$ is a prime harmonious labeling.

Proof: Let $\mathrm{u}_{1}, \mathrm{u}_{2}, \ldots \ldots \ldots \mathrm{u}_{\mathrm{n}}$ and $\mathrm{v}_{1}, \mathrm{v}_{2}, \ldots \ldots \ldots \mathrm{v}_{\mathrm{n}}$ be the vertices of the path $\mathrm{P}_{\mathrm{n}}$.

Define $\mathrm{f}: \mathrm{V}(\mathrm{G}) \rightarrow\{1,2,3 \ldots \ldots \ldots 2 \mathrm{q}-1\}$ is injection.

Then $\mathrm{f}$ induces an edge labelingf $\mathrm{f}^{*}: \mathrm{E}(\mathrm{G}) \rightarrow\{1,2,3 \ldots \ldots \ldots 2 \mathrm{q}\}$ is a bijection. 
Case(1): If $\mathbf{n}$ is odd

Here the vertices are labeled such that $\operatorname{GCD}(\mathrm{f}(\mathrm{u}), \mathrm{f}(\mathrm{v}))=1$ and edges are labeled $(\mathrm{e}=\mathrm{uv})=(\mathrm{f}(\mathrm{u})+\mathrm{f}(\mathrm{v}))(\bmod \mathrm{q})$. Case(2): If $\mathbf{n}$ is even

We define $f: V(G) \rightarrow\{1,2,3 \ldots \ldots \ldots n\}$ by $P_{n}=n+1$ where $n=0,1,2 \ldots \ldots$ Here also the same labeling pattern is followed as in the case 1 . Hence we conclude that the path $\mathrm{P}_{\mathrm{n}}$ admits a prime harmonious labeling.

Prime Harmonious labeling of path is shown in Figure 1

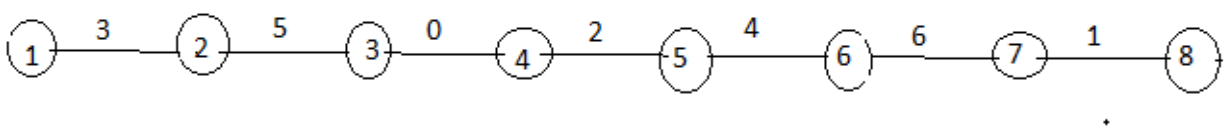

Figure 1

Theorem 2.2: Every comb graph $\mathrm{P}_{\mathrm{n}} . \mathrm{K}_{1}$ is a prime harmonious labeling.

Proof: Let $\mathrm{u}_{1}, \mathrm{u}_{2}, \ldots \ldots \ldots \mathrm{u}_{\mathrm{n}}$ be the vertices of the path $\mathrm{P}_{\mathrm{n}}$.

Let $\mathrm{v}_{1}, \mathrm{v}_{2}, \ldots \ldots \ldots \mathrm{v}_{\mathrm{n}}$ be the vertices adjacent to each vertex of the path $\mathrm{P}_{\mathrm{n}}$.

Define $\mathrm{f}: \mathrm{V}\left(\mathrm{P}_{\mathrm{n}} . \mathrm{K}_{1}\right) \rightarrow\{1,2,3 \ldots \ldots \ldots 2 \mathrm{q}-1\}$ is injection.

Then $\mathrm{f}$ induces an edge labeling $\mathrm{f}^{*}: \mathrm{E}\left(\mathrm{P}_{\mathrm{n}} \cdot \mathrm{K}_{1}\right) \rightarrow\{1,2 \ldots .2 \mathrm{q}\}$ is a bijection.

Hence the graph $\left(\mathrm{P}_{\mathrm{n}} . \mathrm{K}_{1}\right)$ admits a prime harmonious labeling.

Prime Harmonious labeling of Comb $\mathrm{P}_{8} \cdot \mathrm{K}_{1}$ is shown in Figure 2

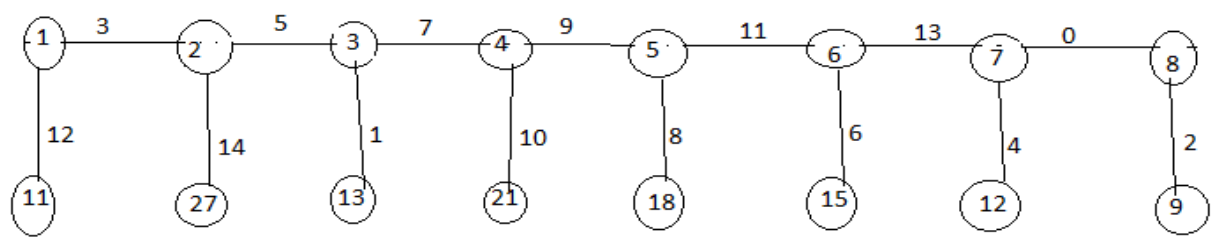

Figure 2

Theorem 2.3: The star $\mathrm{K}_{1, \mathrm{n}}$ is prime harmoniouslabeling.

Proof: Let $V\left(K_{1, n}\right)=\left\{u_{i} / 1 \leq i \leq n\right\}$

Let $E\left(K_{1, n}\right)=\left\{e_{i} / i=1,2,3 \ldots . . n-1\right\}$

Define an injection $\mathrm{f}: \mathrm{V}\left(\mathrm{K}_{1, \mathrm{n}}\right) \rightarrow\{1,2, \ldots \ldots . .2 \mathrm{q}-1\}$ is defined by

$\mathrm{f}(\mathrm{v})=1$

$\mathrm{f}\left(\mathrm{v}_{\mathrm{i}}\right)=2 \quad \forall \mathrm{i}=1$

$\mathrm{f}\left(\mathrm{v}_{\mathrm{i}+1}\right)=\mathrm{n}+1, \mathrm{i}=1,2, \ldots \ldots . \mathrm{n}$.

Then $\mathrm{f}$ induces a bijection $\mathrm{f}^{*}: \mathrm{E}\left(\mathrm{K}_{1, \mathrm{n}}\right) \rightarrow\{1,2 \ldots \ldots \ldots \ldots 2 \mathrm{q}\}$.

In the view of above labeling pattern $\mathrm{K}_{1, \mathrm{n}}$, admits a prime harmonious labeling Prime Harmonious labeling of Star $\mathrm{K}_{1,7}$ is shown in Figure 3

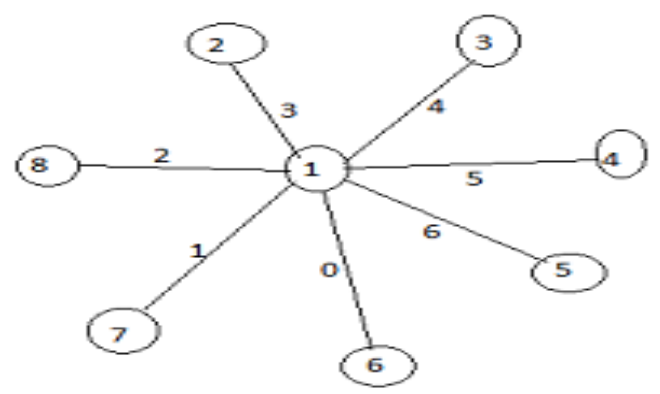

Figure 3

Theorem 2.4: The fan $f_{n}$ is a prime harmonious labeling.

Proof: Let $u$ be the center vertex of the fan $f_{n}$

Let $v_{1}, v_{2}, \ldots \ldots . . v_{n}$ be the vertices of leaves of fan $f_{n}$

Label the center vertex with 1 and path vertices are labeled by 2 to $n$. It contains $n+1$ vertex and $2 n-1$ edges. (i.e) $\mathrm{f}_{\mathrm{n}}=\mathrm{P}_{\mathrm{n}}+\mathrm{K}_{1}$

Joining all vertices of path $P_{n}$ to the center vertex $u$.It satisfies the conditions of $P_{H}$. Therefore the fan $f_{n}$ is a prime harmonious labeling. 
Prime Harmonious labeling of fan $f_{7}$ is shown in Figure 4

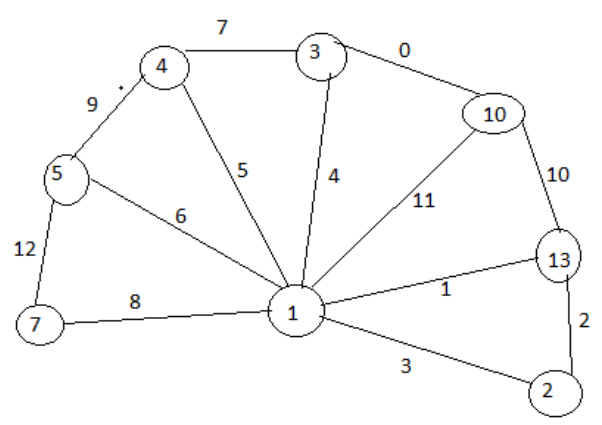

Figure 4

Theorem 2.5: The cycle $C_{n}$ is prime harmonious labeling

Proof:We shall consider the following three cases

Case(1): If $\mathbf{n}$ is odd

Define $\mathrm{f}: \mathrm{V}(\mathrm{G}) \rightarrow\{1,2, \ldots \ldots . .2 \mathrm{q}-1\}$ by $\mathrm{f}\left(\mathrm{v}_{\mathrm{i}}\right)=\mathrm{j}-1$ where $\mathrm{i}=1,2$,

$\ldots n, j=2,3, \ldots \ldots . n$

Then $\mathrm{f}$ induces an edge label $\mathrm{f}^{*}: \mathrm{E}(\mathrm{G}) \rightarrow\{1,2,3$. $2 \mathrm{q}\}$ is bijection.

Therefore the cycle $\mathrm{C}_{\mathrm{n}}$ is a prime harmonious labeling if $\mathrm{n}$ is odd.

Case 2: If $n$ is even $(n \leq 4)$

Define $\mathrm{f}: \mathrm{V}(\mathrm{G}) \rightarrow\{1,2, \ldots \ldots . .2 \mathrm{q}-1\}$ by $\mathrm{f}\left(\mathrm{v}_{1}\right)=1, \mathrm{f}\left(\mathrm{v}_{1}\right)=2, \mathrm{f}\left(\mathrm{v}_{1}\right)=3, \mathrm{f}\left(\mathrm{v}_{1}\right)=7$

Then $\mathrm{f}$ induces an edge label $\mathrm{f}^{*}: \mathrm{E}(\mathrm{G}) \rightarrow\{1,2,3 \ldots \ldots .2 \mathrm{q}\}$

Therefore the cycle $C_{n}$ is a prime harmonious labeling if $n$ is even $(n \leq 4)$.

Case 3: If $n$ is even $(n \geq 4)$

As $n$ is even let $n=2 m$ where $m=3,4 \ldots \ldots m-1$

Let $\mathrm{v}_{1}, \mathrm{v}_{2}, \ldots \ldots . \mathrm{v}_{2 \mathrm{~m}-1}$ be the vertices of cycle $\mathrm{C}_{2 \mathrm{~m}}$.

Adding the vertices $v_{1}+v_{2}, v_{2}+v_{3}, \ldots \ldots \ldots \ldots \ldots, v_{2 m-1}+v_{1}$ we obtain some edges of $C_{2 m}$ are equal, which is impossible.

Therefore the cycle $\mathrm{C}_{2 \mathrm{~m}}(\mathrm{n} \geq 4)$ is not a prime harmonious labeling.

Prime Harmonious labeling of cycle $\mathrm{C}_{9}$ is shown in Figure 5

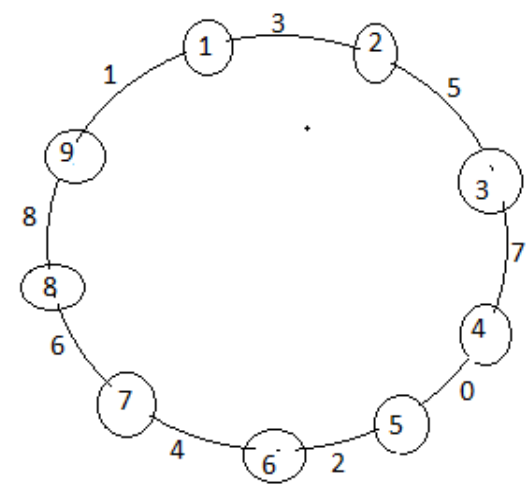

Figure 5

Theorem 2.6: The crown graph $\mathrm{C}_{\mathrm{n}} \cdot \mathrm{K}_{1, \mathrm{n}}$ is a prime harmonious labeling

Proof: Let $\left\{v_{1}, v_{2}, v_{3}, \ldots \ldots \ldots v_{n}\right\}$ be the vertices of the cycle $C_{n}$.

Let $\left\{\mathrm{u}_{1}, \mathrm{u}_{2}, \mathrm{u}_{3}, \ldots \ldots \ldots \mathrm{u}_{\mathrm{n}}\right\}$ be the vertices of $\mathrm{K}_{1, \mathrm{n}}$.

Case (1): When $n$ is odd cycle

The size of the graph is $p=3 n+3$. Define a mapping $f: V\left(C_{n} \cdot K_{1, n}\right) \rightarrow\{1,2,3 \ldots \ldots .(3 n+3)\}$ by $f\left(v_{i}\right)=i+1$ where $\mathrm{i}=0,1,2, \ldots \ldots \mathrm{n}$ and $\mathrm{f}: \mathrm{E}(\mathrm{G}) \rightarrow\{1,2 \ldots \ldots \ldots(3 \mathrm{n}+3)\}$

Case (2): When $n$ is even cycle

The size of the graph is $\mathrm{p}=4 \mathrm{n}+4$. Define a mapping $\mathrm{f}: \mathrm{V}\left(\mathrm{C}_{\mathrm{n}} \cdot \mathrm{K}_{1, \mathrm{n}}\right) \rightarrow\{1,2,3 \ldots \ldots \ldots(4 \mathrm{n}+4)\}$ by $\mathrm{f}\left(\mathrm{v}_{\mathrm{i}}\right)=\mathrm{i}+1$ where $\mathrm{i}=0,1,2, \ldots . . \mathrm{n}$.

Then $f$ induces a bijection $\mathrm{f}^{*}: \mathrm{E}(\mathrm{G}) \rightarrow\{1,2, \ldots \ldots(4 \mathrm{n}+4)\}$

Therefore the crown graph $\mathrm{C}_{\mathrm{n}} \cdot \mathrm{K}_{1, \mathrm{n}}$ is a prime harmonious labeling.

Prime Harmonious labeling of crown graph $\mathrm{C}_{4} \cdot \mathrm{K}_{1,4}$ is shown in Figure 6 


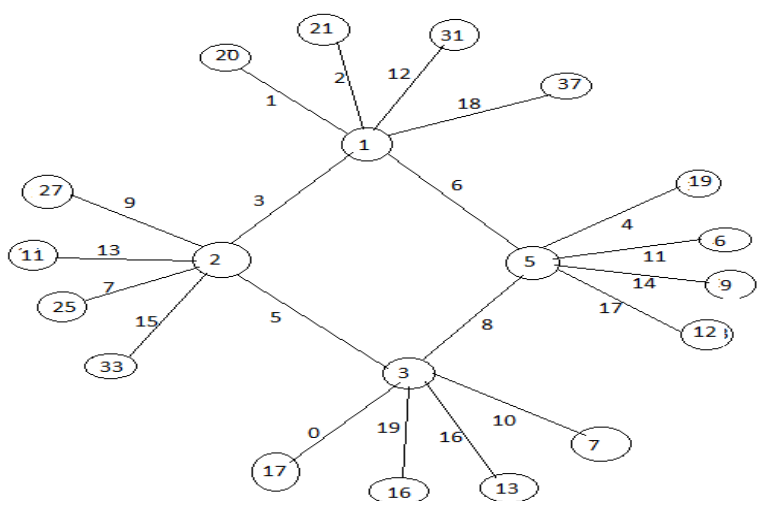

Figure 6

Theorem 2.7: The Bistar $B_{n, n}$ admits a prime harmonious labeling.

Proof: Consider the two copies of $\mathrm{K}_{1, \mathrm{n}}$.

Let $\mathrm{v}_{1}, \mathrm{v}_{2}, \mathrm{v}_{3}, \ldots \ldots \ldots \mathrm{v}_{\mathrm{n}}$ and $\mathrm{u}_{1}, \mathrm{u}_{2}, \mathrm{u}_{3}, \ldots \ldots \ldots \mathrm{u}_{\mathrm{n}}$ be the corresponding vertices of each copies of $\mathrm{K}_{1, \mathrm{n}}$ with apex vertex $\mathrm{u}$ and $\mathrm{v}$.

Let $\mathrm{e}_{\mathrm{i}}=\mathrm{vv}_{\mathrm{i}}, \mathrm{e}_{\mathrm{i}}{ }^{\prime}=\mathrm{uu}_{\mathrm{i}}$ and $\mathrm{e}=\mathrm{uv}$ of bistar graph.

Note that $\left|V\left(B_{n, n}\right)\right|=2 n+2$ and $\left|E\left(B_{n, n}\right)\right|=2 n+1$.

Define the labeling $\mathrm{f}: \mathrm{V}\left(\mathrm{B}_{\mathrm{n}, \mathrm{n}}\right) \rightarrow\{1,2,3 \ldots \ldots \ldots|\mathrm{V}|\}$

Then $\mathrm{f}$ induces an edge labeling $\mathrm{f}^{*}: \mathrm{E}\left(\mathrm{B}_{\mathrm{n}, \mathrm{n}}\right) \rightarrow\{1,2,3 \ldots \ldots .2 \mathrm{n}+1\}$ is bijection.

In view of above labeled pattern $B_{n, n}$ admits a prime harmonious labeling.

Prime Harmonious labeling of Bistar B8, 8 is shown in Figure 7

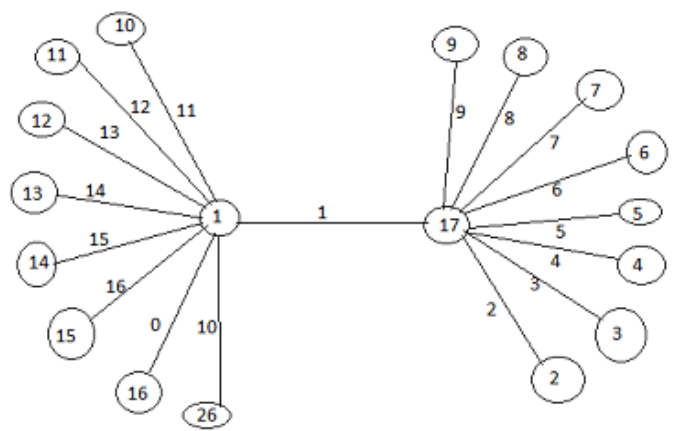

Figure 7

Theorem: $2.8 \mathrm{M}\left(\mathrm{P}_{\mathrm{n}}\right)$ is a prime harmonious labeling.

Proof: Let $v_{1}, v_{2}, v_{3}, \ldots \ldots \ldots v_{n}$ and $e_{1}, e_{2}, e_{3}, \ldots \ldots \ldots e_{n-1}$ are respectively be the vertices of $P_{n}$.

Add vertices $\mathrm{u}_{1}, \mathrm{u}_{2}, \mathrm{u}_{3}, \ldots \ldots \ldots \mathrm{u}_{\mathrm{n}-1}$ corresponding to the edges $\mathrm{e}_{1}, \mathrm{e}_{2}, \mathrm{e}_{3}, \ldots \ldots \ldots \mathrm{e}_{\mathrm{n}-1}$ in order to obtain middle graph.

Let $\mathrm{G}$ be the graph $\mathrm{M}\left(\mathrm{P}_{\mathrm{n}}\right)$. Then $|\mathrm{V}(\mathrm{G})|=2 \mathrm{n}-1$ and $|\mathrm{E}(\mathrm{G})|=3 \mathrm{n}-4$

Define the mapping $\mathrm{f}: \mathrm{V}\left(\mathrm{M}\left(\mathrm{P}_{\mathrm{n}}\right)\right) \rightarrow\{1,2,3 \ldots \ldots \ldots|\mathrm{V}|\}$

Then $f$ induces an edge labeling $\mathrm{f}^{*}: \mathrm{E}\left(\mathrm{M}\left(\mathrm{P}_{\mathrm{n}}\right)\right) \rightarrow\{1,2,3 \ldots \ldots .3 \mathrm{n}-4\}$ is bijection and it is satisfies the conditions of prime harmonious labeling.

Prime Harmonious labeling of $\mathrm{M}\left(\mathrm{P}_{8}\right)$ is shown in Figure 8

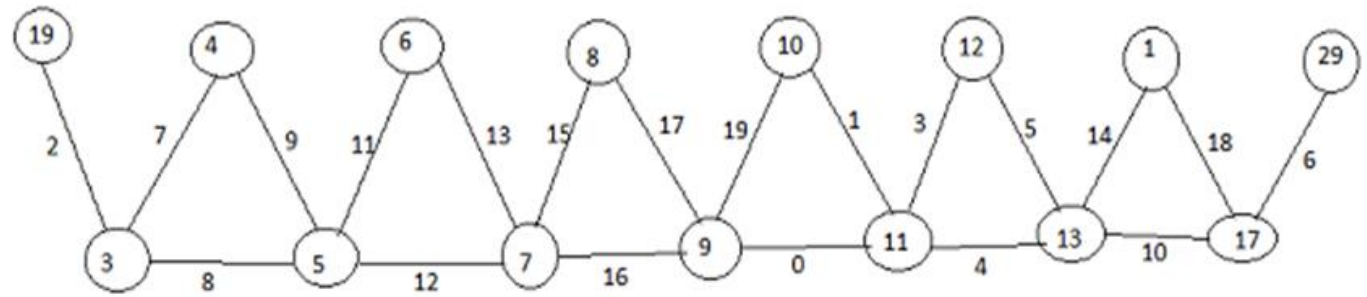

Figure 8 
Theorem: 2.9: The graph $\mathrm{P}_{\mathrm{n}}^{2}$ is a prime harmonious labeling.

Proof: Let the vertices of $\mathrm{P}_{\mathrm{n}}{ }^{2}$ be $\left\{\mathrm{v}_{\mathrm{i}}: 1 \leq \mathrm{i} \leq \mathrm{n}\right\}$ and the edges of $\mathrm{P}_{\mathrm{n}}{ }^{2}$ be $\left\{\mathrm{v}_{\mathrm{i}} \mathrm{v}_{\mathrm{i}+1}: 1 \leq \mathrm{i} \leq \mathrm{n}-1\right\} \cup\left\{\mathrm{v}_{\mathrm{i}} \mathrm{v}_{\mathrm{i}+2}: 1 \leq \mathrm{i} \leq \mathrm{n}-2\right\}$. We first label the vertices of $\mathrm{P}_{\mathrm{n}}{ }^{2}$ as follows :

Define $\mathrm{f}: \mathrm{V}\left(\mathrm{P}_{\mathrm{n}}^{2}\right) \rightarrow\{1,2,3 \ldots \ldots \ldots \mathrm{n}\}$ by $\mathrm{f}\left(\mathrm{v}_{\mathrm{i}}\right)=2(\mathrm{i})+1,1 \leq \mathrm{i} \leq \mathrm{n}$

Then the induced edge labels $f^{*}(E(G)): f^{*}\left(v_{i} v_{i+1}\right) \cup f^{*}\left(v_{i} v_{i+2}\right) \rightarrow\{1,2 \ldots \ldots .2 n-3\}$ is bijection.

Therefore $\mathrm{P}_{\mathrm{n}}{ }^{2}$ satisfies the condition of prime harmonious labeling.

Prime Harmonious labeling of $\mathrm{P}_{7}{ }^{2}$ is shown in Figure 9

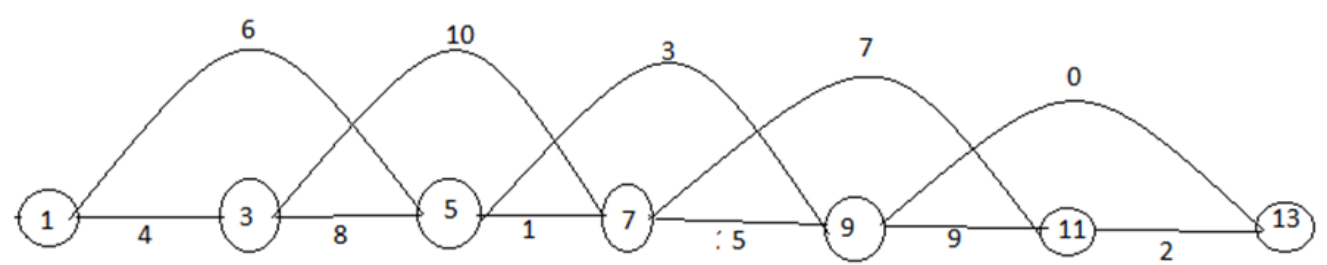

Figure 9

\section{Conclusion}

The harmonious labeling is one of the most important labeling techniques. Here we introduce the new concept of prime harmonious labeling of some new graphs and it is very interesting to investigate a graph family which admits prime harmonious labeling. In general, all the graphs are not prime harmonious labeling.

\section{References}

[1]. E. L. Aldred and B. D. Mckay, Graceful and harmonious labeling of trees, personal communication.

[2]. Dushyant Tanna, “Harmonious Labeling Of Certain Graphs"(IJAERS) E-ISSN 2249-8974

[3]. Gallian, J.A.(2010).A dynamic survey of graph labeling, The Electronics Journal of Combinatorics, 17 (\#DS6).

[4]. R. L. Graham and N.J.A. Sloane, on additive bases and harmonious graphs, SIAM, J. Alg. Disc. Meth. 1, (1980), 382 - 404.

[5]. J. Gross and J. Yellon, "Graph Theory and its Application" CRC Press , Boca Raton, 1999.

[6]. Dr . Manonmani and R. Savithiri , Some New Results on K - Even Sequential Harmonious Labeling of Graphs.(LRG Govt. Arts College(W), Tirupur- India)

[7]. A. Rosa, On certain Valuations of the vertices of a graph, Theory of Graphs (International Symposium, Rome, July 1966), Gordan ad Breach, N.Y. and Dunod Paris (1967) 349-355.

[8]. S.Uma Maheswari and Dr. K. Indirani, “Difference Speed Sequence Graph”, (IJMTT) - Volume 33 November 2-May 2016

[9]. S.K. Vaidya and N .H. Shah, "Some New Families Of Prime Cordial Graphs," Journal of Mathematics Research.Vol 3, No.4, 2011,pp 21-30. 